\title{
Archaeology as a Public Good WAE
}

Stanton Green, Anthropology Monmouth University, West Long Branch, New Jersey, USA

E-mail: stanton.green@gmail.com

Claudia Green, Independent Archaeologist, West Long Branch, New Jersey, USA

Joseph Schuldenrein, Geoarchaeological Associates, New York, USA

Accepted: 27 January 2021 / Published online: 25 March 2021

To the people of Arkansas and their elected representatives, who together have had the foresight and determination to blaze new trails in archaeological legislation and public support, and by so doing have provided Arkansas with a potential for the best state programme of archaeological research, preservation, and development in the country.

Charles McGimsey's (1972) dedication to his groundbreaking book Public Archaeology.

\section{Creating a New Public Archaeology}

Over the past half-century, American archaeology has evolved from a largely academic research pursuit into a publicly funded practice. McGimsey's 1972 pioneering volume, Public Archaeology, explicitly recognized archaeology's accountability to the public, perhaps for the first time. In so doing, he challenged the discipline to justify itself as a public good. His broad justification for pursuing archaeology was based on links between "research, preservation, and development" by which we would understand to include economic development. It is a concept that awakened the archaeological community to contemporary relevance and merged the origins and reach of preservation to broader interests of the emerging environmental movement of the late 1960s and '70s.

Legislators began recognizing these links between research, historic preservation, and the public good with the Antiquities act of 1906. Ultimately, the Environmental Protection Act of 1968 institutionalized public archaeology as a part of environmental protection. McGimsey's published announcement was fundamental to the next half-century of archaeological practice. Since then, the ranks of professionals pursuing academic archaeology were eclipsed by those in Cultural resource management (CRM) in the 
1970s and '80s. University teaching positions declined dramatically in the mid-1970s, while CRM funding skyrocketed with the push for economic growth, infrastructure improvement, and land development across the US. Such expansive programmes created large pools of funding through state and federal contracts filling the gaps left by the diminishment of academic jobs and traditional NSF and NEH type grant funding on which academic archaeologists had been relying. The pace and scope of change in a re-prioritized environmental/preservation landscape began to impact the archaeological profession in a variety of ways that have, arguably, altered the field's reach.

Within the discipline, CRM and academic archaeologists often clashed in terms of the importance of their rationale for doing archaeology. Academic archaeologists often "pulled rank" on CRM archaeologists, drawing largely on the traditional prestige afforded to university professors. From the academy's perspective, CRM archaeology was akin to digging up artifacts with little if any research purpose or significance. Terms like "salvage archaeology" reflected this attitude by portraying the practice of CRM as unsystematic emergency recovery. Students were caught in the middle of this dispute. They were typically taught by theory-driven professors and hired by CRM business firms. At the same time, universities were being squeezed by the withdrawal of public funding and the increased pressure to provide students with career preparation.

Archaeologists in CRM justified their practice in the terms of the preservation of the past. Many justified the ethics of the practice by underscoring efforts to mitigate adverse impacts. Unqualified site destruction and rampant land development were slowed or (more rarely) modified in the interests of preservation. Academic archaeologists typically argued that research needed to focus on the creation of knowledge for knowledge's sake. With time, large budgets sustained and magnified the profile of CRM, ultimately placing it at the centre of archaeological practice. Nevertheless, the dialectic between theoretically-based archaeology and practically-based fieldwork continued. At first, this competition between these two professional sectors seemed almost tribal, with each developing its own belief system to justify its practice. University-based archaeology careers had traditionally been the most prized. Over time, economic realities took over as Ph.D. archaeologists began to build substantial careers in CRM. Although the public contracts that funded CRM work called for data-driven reports as their deliverables, CRM archaeologists continued to participate in academic conferences and many began to produce reports that produced substantive and quantitative data that allowed for answering broader culture-historic and theoretical questions. CRM-based research found its way into publication in scholarly journals. At the same time, university archaeologists began to take on CRM work to fund their research. As a result, the divide 
between contracted archaeology and research-driven archaeology began to diminish.

This dialectic between CRM and academic archaeology led to a variable consolidation of research and practical applications to create what we would call a "new public archaeology", which many now call heritage studies. Cultural heritage refers to a community's pride in its cultural past and geographical place. No more powerful a voice than Nelson Mandela's proclaimed the profundity of heritage as a driver of public well-being.

Our rich and varied cultural heritage has a profound power to help build our nation.

This notion of heritage precisely aligns with archaeology's mission to study the cultural past. A major component of a community's heritage is the cultural attachment to place (Green \& Green, 1999). Ireland's poet laureate Seamus Heaney speaks to the heritage and place dynamic through much of his poetry, underscoring the profundity of the cultural landscape in his essay "A Sense of Place".

Irrespective of our creed or politics, irrespective of what culture or subculture may have coloured our individual sensibilities, our imaginative assent to the stimulus of names, our sense of place is enhanced, our sense of ourselves as inhabitants not just of geographical country but country of the mind are cemented. It is this feeling of assenting, equable marriage between the geographic country and the country of mind, whether that country of mind takes its tone unconsciously from a shared oral inherited culture or from a consciously savoured literary-culture, or from both, it's this marriage that constitutes the sense of place in the richest possible manifestations (Heaney, 1972).

Cultural heritage attaches each human community to the history of its natural, physical, and social environments. It anneals the culture and history of a community's values, beliefs, politics, and material culture. It combines community pride as the cultural-historical background upon which to build a sustainable future. It provides a vehicle for traditional knowledge to be brought forwards within an understanding of how things have changed over time and how they must change in order to provide for a successful future. There is, we would argue, no more powerful basis for living in the present and preparing for the future than a heritage built on an accurate understanding of past culture. We would take Willey and Phillips (1958) and Binford's (1962, 1978) assertion that "Archaeology is Anthropology or it is nothing at all", one step forwards to say that archaeology as anthropology is the most powerful force for building the cultural heritage needed to propel a culture forwards successfully and sustainably. 
Cultural-ecological history provides perhaps the most obvious example of what we need to carry forwards from our knowledge of the past. The change from living as part of the ecosystem like hunter-gatherer-fisher societies largely do, to living apart from nature as farmers do, is the most profound cultural shift of our species.

The modern world, however, has been on a trajectory to dominate the environment, effectively altering the balance between the maintenance of the human condition and replenishing the planet's natural resources. The process began by small and then larger-scale land clearing and planting. Ultimately, near rampant extraction of fossil fuels has placed the planet on the defensive. Economies have used models of growth that rely on nonrenewable fossil fuels, and non-sustainable forest clearing and harvesting technologies. The scale of such change is ominous and readily apparent. Over the past 100 years (or less), for example, subsistence has relied on overfishing of the seas. We have subsequently domesticated the seas as we had domesticated land. This process of ocean domestication has been nearly invisible, and we suspect the same was true for the prehistoric domestication of cereals and animals. Fish, unless specifically designated or individually caught, is raised on fish farms. Wild foods such as hook-line caught tuna are rare and exceptionally expensive. Wild game has persisted as part of some people's diets for the past 10 millennia, but only as a tiny percentage. Yet on the whole our awareness is limited to our own communities, while others that are not yet overly concerned (or impacted) remain to confront the realities of a non-sustainable environment.

Public awareness of the human-environmental past is fundamental to solving today's climate and ecological crises. There is now an awareness of the need for dynamic equilibrium between human activity and the maintenance of the natural biosphere in the interests of sustainability and ultimately human survival.

In this connection a favourite story of mine (Stan Green, here) illustrates the power of the past. Archaeologists are often asked their specific reasons for studying archaeology. The questioners usually expect the response to centre on artifacts, sites, or even regions of the world. For some of us, our interest lies in the consequences of farmers on the natural environment. A second question is then posed: “Haven't we always been farmers"? The easiest response to this is a five-minute version of the 100,000 year prehistory of our species to show that farming is indeed a recent adaptation. The bottom line is that people have been inculcated with the unfounded notion that we have always been farmers. And logic moves ahead to the assumption that farming is a natural succeeding adaptive strategy to hunting-gathering (even instinctive in some people's minds). Discussion rarely delves into non-linear understanding of adaptive transformations, despite the causes and consequences of the impacts to 
human economies that were driven by adaptive change derived from many sets of adaptive changes on the planet. The lesson is that when we began to farm, we changed as a species from being $a$ part of the environment to one being apart from the environment and therein lies our current enviroclimate crisis. That line of thinking is now playing itself out on a global scale.

Archaeology undertaken within its environmental historic context reveals the human ecological patterns of prehistoric settlement in ways relevant to current economic change. The Irish fishing village of Dunmore East in southeastern Ireland (Waterford County), by way of example, has been going through economic decline because of overfishing and exporting of fish to China and other regions of the world (Green et al., this volume). The decline of the industry has robbed the community of its livelihood and its identity, which remains tied to its fishing heritage. At the same time, coastal erosion resulting from sea level rise is further damaging the beaches on the margins of the regional estuary, with deleterious results to many of Ireland's coastal settlements.

Recovery of the community's cultural heritage goes hand in hand with saving the landscape. Municipal authorities and the business community are aware of these negative trends and their causes. Planners and agencies are working with archaeologists to explore the ways in which traditional lifeways may be revived not only to reinvigorate (in an adaptive sense) the fishing economy but also to develop an eco-and heritage tourism industry.

\section{Case Studies I: The Editors' Perspectives}

The three editors of this volume have worked through this transformative period of archaeology and it is our experiences that underlie the assertion that the integration of CRM and academic archaeology has resulted in enhancing archaeology as a public good, while at the same time benefiting the development of archaeology as social scientific intellectual discipline. We draw first on Stan and an example from his professional history. These accounts are presented in a first person telling, so as to convey the emotions and recollections of the practitioners.

Stan Green

My example is taken from an early CRM archaeological project (Green, 1977; Green \& Brooks, 1978) in Huger, South Carolina. The endeavour was funded by a private corporation to meet its environmental protection requirements. Environmental compliance required an archaeological survey to determine if there was evidence of prehistoric and historic settlement along the ridge where a train track was planned to service an industrial factory. I implemented the survey as a classic small summer contract. It 
should be noted that in these early days of CRM, the structure and protocol for undertakings were considerably less formal and standardized than they are today. Accordingly, I ran the contract between semesters, while teaching at the University of South Carolina. The project objective was to systematically look for archaeological evidence on the ridge on which they were building a railway track and to mitigate the impacts of any damage to the archaeological record should significant archaeological evidence be found. As in many projects of this kind, the tasks involved both archaeological survey and an evaluation of significance under terms of Section 106 of the National Historic Preservation Act (NHPA 1966). To satisfy these objectives, my approach was to meet compliance requirements while at the same time acknowledge that the significance determination rested on the methodology applied for successful survey. Although the contractor was only interested in knowing if there was significant evidence of previous settlement in the area of potential effect (APE), I used this field opportunity as a way to investigate a then pivotal methodological question in survey archaeology: How do sampling strategies affect the discovery and interpretation of archaeological sites? Thus, the fieldwork strategy attempted to integrate legal contract concerns with broader-based archaeological research questions.

The finished product of the work (formally the "deliverables") was designed to speak to both the contractor and to archaeological peers. To address these dual concerns, the project budget included funding for both the report and the travel expenses for an academic presentation to the Society for American Archaeology (SAA). The resulting publications included a report of the findings of scattered native American pottery sherds along the ridge, and local and national presentations on the relationship of spatial sampling methods and the definition of sites. The site was recorded, and no further investigation was recommended. This recommendation was made within a theoretical conversation of what it in fact defines an archaeological site. The survey methodology indicated random scatter and my assistant Mark Brooks and I concluded that although the scatter was legally recorded as the Huger site, it was not bounded in any way that would indicate anything other than ephemeral use. (Green \& Brooks, 1978a, b).

Joseph Schuldenrein

My example is a classic preview of how traditional (Native American) stakeholders, corporate interests, CRM archaeologists and government regulators can interact to resolve delicate compliance issues in the public interest. In this case, potentially disastrous results were averted because the parties worked tirelessly in the spirit of cooperation, fully aware that compromise was the only solution. I was the Co-Principal Investigator for the archaeology team. The project was a 200-mile gas pipeline that ran from 
Ontario, Canada, west to east across New York State. Because of in-service utility deadlines, a maze of regulatory requirements, uncertain (at the time) CRM protocols, and Native American concerns, each party had its own priorities that often pitted its interests against those of others. Here, as elsewhere, the pipeline company's construction practices were best considered piecemeal assembly of the line, segment by segment. While design engineering factored into the initial strategy, the maze of regulatory statutes at the time was so complex that continuous linear construction was nearly impossible. Thus, when a certain segment of the proposed design had cleared objections and compliance hurdles that portion of the pipeline trench was excavated and its segments were pieced together. Where complex environmental and compliance issues remained, a particularly sensitive environmental gap was left in the line, presumably to be filled when related issues were resolved. Key areas of dispute, both generally and in this case, included state nature preserves, wetlands, and a major Native American reservation that was the traditional home of the Tonawanda band of Seneca.

As fate would have it, the entire line, with a single exception, was eventually cleared more than two years behind schedule. The exception segment confronted compliance issues that seemed intractable. To complicate matters further, in-service operations were weeks away without resolution, despite the awareness and best efforts of all parties to resolve it. The fly in the ointment was a disputed parcel of land that had to be traversed, while running afoul of numerous compliance issues. The property straddled the boundary of a New York State Wetlands preserve; on disputed land without a recognized border between the State Preserve and the accepted end of Seneca lands, and on terrain that archaeological survey had demonstrated was a potential burial ground. The New York State Department of Parks and Recreation informed the pipeline company on numerous occasions that there were simply too many hurdles to clear. And yet there were absolutely no alternative routes that would facilitate a continuous flowthrough line. Even before this disputed segment of the project sank deeper and deeper into conflict, the pipeline company had worked with the Native Americans and our CRM team to overcome the then controversial issue of Native American graves and repatriation. Over the course of several months, pipeline executives and archaeologists worked closely with Native Americans to delineate and define the extent and distribution of burials. In the interests of cooperation, the company hired the Seneca in several monitoring capacities, most notably for the archaeological surveys and to staff monitoring stations along the length of line. The latter became fulltime jobs. In the interim, strong alliances were formed amongst these three parties, which turned out to be a wise long-term decision. The company made sure to involve the New York state Bureau of Indian Affairs well in 
advance of all construction activities. Over several months, protocols were worked out for repatriation or preservation contingent on mapping and defining the reach of the presumed burial site. The tribe provisionally agreed to remove isolated burials if encountered in a narrowly defined (APE) of the pipe trench, also known as a "bottleneck" especially near the crossing of the primary drainage-way (most sensitive for buried cultural resources). Further staffing for any and all pipeline maintenance activities was exclusively granted to the Tonawanda on reservation grounds and in advisory capacities beyond. Such progress notwithstanding, the New York State Historic Preservation Office remained a more passive partner in the effort, in part, because as mentioned, the multiple ecological and preservation constraints rendered construction through the proposed "bottleneck" impossible. The final obstacle that threatened to derail the project was the discovery of a bone fragment in a cut bank of the aforementioned river crossing that the Seneca indicated might preclude their approval IF the bottleneck itself yielded significant numbers of burials. The bone was left untouched and unidentified. The Seneca chiefs, unbeknownst to any of the parties, had deliberated on the "bottleneck" issue on a brisk Saturday morning in April; this was the day the parties had scheduled to bring out a physical anthropologist to identify the bone fragment in advance of final consultations.

Final resolution almost followed the script of a suspense thriller. As the sole representative of the archaeological team, I was invited to a Seneca pipe smoking ceremony on the south bank of the river that Saturday morning at dawn. As the ceremony proceeded, the bone was slowly inspected and excavated by the physical anthropologist and an assistant. It was a captivating experience, as one of the chiefs told me that I would be amongst the few non-natives to ever experience this ceremony. One of the elders mentioned that the ceremony was the equivalent of a prayer to the spirits, seeking guidance for a decision over which the Seneca Council had deliberated over the course of several weeks. The ceremony took place in a clearing between two forested stretches on the ridge that housed several of the previously identified burials. Sacred and hallowed ground. It was almost mystical. The ceremony was a little short of cathartic. It was the sort of experience that one never forgets, given the strength of place and time (as we have discussed above). But most significantly, I was struck by the power of cross-cultural tolerance and enrichment amongst the diverse parties with even more disparate interests in the project and its underlying processes. I felt both honoured and frightened at the same time. I felt honoured, insofar as I had developed such a close rapport with these wonderful partners and helped to shepherd a process that many had thought would never happen. And yet I remained frightened that it would ultimately fall on my shoulders to inform the pipeline president that a critical 
eleventh-hour finding could stall the process and result in a delay of inestimable costs so close to the in-service schedule. This was not the type of wrath I had originally signed up for.

As I emerged from the ceremony and made my way down to the river bank, accompanied by Seneca chiefs and elders, I was called aside by the physical anthropologist, then a junior professor at Buffalo University. Her voice was shaky, and she was clearly unnerved. She whispered in my ear and informed me that the bones were not human. They belonged to an elk! I was little short of stupefied. I was still in the throes of a cathartic moment and then essentially whacked into a form of shock that challenged every reserve of clear thinking that worked its way through my brain. What to say to the Seneca? How to make that phone call to the company president?

When I came to my senses the options were clear. Talk this out with the Seneca in advance of contacting the president. I approached the elders cautiously but firmly. In my most stoic manner, I simply blurted out something like, "Gentlemen, it is an elk!" I turned and stared at the faces in front of me for what seemed to be an eternity. Realistically, it must have been closer to a minute. My eyes focussed on one face after another, and then, I saw what I took to be a bemused expression on the face of one of the younger chiefs named Darwin. His lips spread slowly at first, an expression that turned into a smile and then soft laughter. The rest of the party, as if on cue, followed suit. I was perplexed, probably flustered, and slowly one by one, the elders approached me and patted me silently but gently on the back. One of the heads of the Band was the last to approach me, clearly relieved but sensitive to my obvious frustration. He looked me straight in the eye and said simply "Joe, you did good, really good!" I suppose I should have felt a sense of relief, but I did not. Because my next task was to call the president of the pipeline. Immediately. At 9 am on a Saturday.

Without thinking much about it, I called his number in Michigan and he had, apparently, been anticipating the call and he got right to it. "Well? What the heck is going on"? "It is an elk, Jim, an elk!" "What the...." He was speechless for a moment and then burst out into a hellacious laugh that was apparently heard across the entire meadow where members of our party were simply standing around, grinning and talking and figuring out if we should all go to breakfast somewhere. Jim finally said, "So I guess we are finally done, are not we? I answered in the affirmative. "Good. Breakfast is on me. Lunch is on me. Go back home and get some sleep. We will talk some time next week. An elk? Really, An elk? That is what caused all the ruckus"?

But the story does not end here. The immediate upshot of this drawnout negotiation was the approval and construction of the pipeline, the 
establishment of a sustained and co-operative partnership between a disenfranchised minority and a development interest, and the expanded role of the archaeologist as facilitator and educator. But in a greater sense, it was these types of co-operative engagements in the pivotal 1980s that gave rise to one of the most significant pieces of CRM legislation to date: the passage of NAGPRA, the North American Graves Protection, and Repatriation Act in 1990. This act mandates that "the human remains of any ancestry must at all times be treated with dignity and respect". Oh, yes, so whatever happened to the Office of the New York State Parks, Recreation and Historic Preservation? The only active party that roundly opposed the project? The long-standing SHPO or the voice of that office was unceremoniously let go in the wake of this resolution. Talk about the public good!

\section{Claudia Wolfe Green}

I participated in a major CRM project that involved surveying a portion of the huge river floodplain and terrace complex being flooded by damming of the Savannah River. My story is a great example of how archaeology serves the mission of the National Environmental Protection act of 1968, while having some serious negative side effects on the contemporary local communities (Poplin et al., 1978, 1979).

I stumbled into anthropology after taking a required social science course to fill out my general education requirements. I fell in love with primates and started studying them, until a departmental sea change occurred. The primatologist left and archaeologists moved in. Both new faculty members, Stan Green and John Justeson, were mired in archaeology theory and glyphs. But CRM was afoot. Armed with only the most basic understanding of archaeological theory and an abstract concept of a site and an artefact, I got hired on to the Richard B. Russell Dam project in 1977. I was paid $\$ 2.50$ an hour for a 38- and-a-half hour week. We worked 10 days on followed by three days off from 6 am to $4 \mathrm{pm}$. We did lab work in the evening. This was a standard CRM work schedule. This was my bootcamp and like many, archaeological projects it took place during the South Carolina summer where daily temperatures hovered between 90 and 100 degrees Fahrenheit.

The Russell Project, as it came to be known, aimed to mitigate adverse archaeological impacts of the damming of the much beleaguered Savannah River. The Savannah is the dividing line between South Carolina and Georgia. At the time, there were already two dams that altered its natural flow: the Clark Hill Dam and the Hartwell Dam. The Russell Dam and consequent Lake Thurmond were thrown right in between them. Down river on the Coastal Plain sits the Savannah River Nuclear Plant, brought to South Carolina by Senator Strom Thurmond. Poor Savannah River.

The research design for the project was written by a man who got his archaeological education from legendary archaeology theoretician, Lewis 
Binford. The strategy called for mapping out random transects along the projected reservoir flood zone and the many ridge tops, designated as camping, fishing, and boating access areas. We walked this huge area systematically for months. We covered the bottom-land, terraces, hills, slopes, and ridge tops.

To cut to the chase, the research sampling did not work. Why? Because you cannot see any artefacts underneath six to twelve inches of leaf litter, brambles, trees, and poison ivy. The transects had been planned as if we were in a desert, but we were actually in an inter-riverine zone of the South Carolina and Georgia Piedmont. The transect's equally spaced test pits often occurred on steep slopes or where trees were growing. We soldiered on with snake leggings, backpacks, machetes, shovels, and small shaker screens for each crew. It was a whole day to drive, walk, and then, we were only able to execute a single transect. Typically nothing was found.

A radical new approach became necessary. The dry deserts of the southeastern US are nothing like the forested river valley of the southeastern US. Within two weeks, it became clear that the transects could only be suggestions and the area closest to the transect would be our areas of search and discovery. The sampling strategy became a systematic walk of approximate transect lengths along adjacent ploughed fields, road cuts, and clear cuts. For months we then walked the open land provided by modern land use. Research design meets existing open ground and reality. We started in June and worked through October using a wood-stove found discarded in the back of the fieldhouse-archaeological reuse of refuse. So much of the area had been destroyed by ill-conceived upland cotton plantations. So much of the landscape was wiped clear of topsoil. The clear cuts were the worst fresh gouges to the earth that had been exploited by over-farming. There were days where one would walk a sand loam field full of sorghum (used to make molasses) where artefacts would be found sitting on a pedestal of earth looking to be picked up.

We were there to protect the resources about to be destroyed by the big power companies charged with producing electricity and profits. Their efforts were backed by powerful politicians who were looking to bring in jobs to the area. One day was particularly special in pointing out the dynamic between the role of the environmental protection mission with the existing use of the land by poor land-owners. We drove down a lushly bordered little pond to the most perfect of southern houses. The place was occupied by two sisters in their 70s. We found artefacts behind their house, specifically concentrated above a little creek bed tributary to the south, in Abbeville County. We told the sisters that we were looking for sites because of the environmental impact statement requirements that protected cultural resources. In theory, if we found something really great the project could be halted or modified. One sister looked at our crew and said, "We so, so 
hope you do". I was 21 and worked on all aspects of the Russell Archaeological Project. My archaeology colleagues and I were wrapped up in the discovery and documentation of archaeological resources. The sisters' hope rested in part on our work.

It was not until I went back 15 years later with my parents and kids that I realized the scope and extent of the impact of the dam-based reservoir. The last time I travelled there was when we drove through the project area in 2015 on our way to the Southeastern Archaeological Conference (SEAC) in Athens, Georgia. The area was in complete economic and social decline. The towns that still existed were barely functioning. Such was the impact of this US Army Corps of Engineers project on the modern-day settlement of the region.

By the end of our first season in the Russell Project, I could easily spot quartz, flint, and pottery in land clearings. I learned to wash, catalogue, and analyze what we found. This fieldwork sparked an interest in me that has not since flagged. I still love the Piedmont of South Carolina and Georgia. I learned the counties and the history of my adopted state. And I cannot walk anywhere without looking down to search for artefacts or stones. I still find it really hard not to screen the dirt when I dig my garden. This experience informed our fieldwork in southeastern Ireland, which started shortly thereafter.

As important as the methodological skills that I brought to our Irish project are the lessons of understanding the complexities of preserving the past in ways that enhance the lifeways of contemporary communities.

\section{The Creadan Head Archaeological Project}

Our current project in southeastern Ireland detailed in this volume generally draws on our experiences in North America. We have noted the unique influence of time and place in sharpening the sensitivities to culture and heritage. In North America, the broader impetus to such sensitivities was enhanced by a revolution in environmentalism in the late 1960s, as the impacts of accelerated destruction to landscape were felt on a national scale. Fortunately, federal legislation was passed in recognition of the unavoidable deleterious impacts of poor to unregulated development that accompanied economic expansion and growth. Preservation became a concern largely because progressive movements understood that our historic (and prehistoric) past and their remains were not renewable resources and that once gone, our heritage was gone with them. On a global scale, heritage preservation has had longer and, arguably, deeper traditions than these of the New World. Nevertheless, environmental destruction and 
preservation were linked almost everywhere so that the wave of the $1960 \mathrm{~s}$ carried on internationally.

But it is a different time now. While the environmental movements alerted us to the perils of ecological destruction, the twenty-first century has, in fact, accelerated the extent and pathways of such destruction because of the greater reach of climate change and the emerging crisis of sustainability. There is a keener awareness of the immediacy of these issues on a planetary scale. This has forced responsibility on all sectors of any nation's protective arms (government and private sector) because the failure to respond is simply not an option.

Along these lines, the Creadan Head Archaeological Heritage Project acknowledges the public responsibility to link research, preservation, and development in a community-based, public archaeological project. We are currently researching the archaeology of the Waterford Estuary as the knowledge basis for the development of a regional heritage and economic development for County Waterford in order to stimulate eco-heritage tourism. To do so, we are collaborating with municipal agencies and the local university to integrate our research into their formal economic development plans.

\section{The Case Studies II: The Authors' Perspectives}

Each archaeologist in this volume describes an exemplary case of how archaeology contributes profoundly to a contemporary community's coherence, vitality, and its sustainability. The public good of these projects is channelled via economic development, tourism, environmental protection, education, and even psychotherapy and biomedical research. Taken together, we believe that these studies connect and combine the past and the present into a coherent understanding of the deep-seated foundations of heritage as a cultural force in today's world. They identify the importance of culture history and the resonance of place as the basis of community heritage. This volume's demonstration of archaeology as a public good is provided through case studies on how effective archaeology can serve communities' needs by meeting their economic, environmental, and educational needs.

Lisa Rankin and Barry Gaulton underscore the efficacy of public archaeology as a means to improve the quality of life of modern fishing villages in Newfoundland. Community members young and old participate in the archaeological and historical investigation of the village in ways that prepare them to carry on heritage and tourism projects and even more to teach them marketable technical and communication skills required in the broader employment environment. 
The research and teaching within these community archaeology projects derive from Memorial University's mission to meet the public good of Newfoundland and Labrador. Rankin and Gaulton use the integrative cultural-historical framework of decolonization to advance the pragmatic needs of economic development within a strong sense community heritage and pride.

William Iseminger describes five decades of research and educational outreach at arguably North America's most significant prehistoric site, the Cahokia Mound complex in Illinois. An expanded information centre educates the public about the achievements and vibrancy of Native American Culture and Society through the lens of archaeology. At the Cahokia Museum and site, the public learns how archaeology is practiced, how modern archaeological practice has expanded the knowledge base exponentially in the past 30 years, and ultimately why such knowledge is pivotal to guiding our way forwards. Iseminger provides a detailed description for how archaeological interpretation can be used in an interactive educational setting.

Jordan Ralph, Claire Smith and their fellow Australian archaeological partners demonstrate archaeology's public good in the most personal way: by helping local indigenous communities identify, record, and map the unmarked graves of their ancestors. But the key to the transformative nature of their projects lies in the way they utilize mortuary archaeology as a driver for the economic development of remote aboriginal communities.

Timothy Dodson affords his experience in CRM to describe a communications disjunctures between federal legislation and regulation, land developers, and professionals charged with environmental impact assessment. Each of these stakeholders simply speak different preservation languages. He proposes a "Rosetta Stone" of equivalencies between terms used by government agencies, archaeologists, and land developers. This may sound simple, or even formulaic, but as all anthropologists know, translation is both an art and a science, and Dodson's paper is especially helpful in starting the process for developing a public archaeology dialect.

Joe Joseph's exemplary work through his company, New South Associates, provides case studies where politics, history, heritage, and job and career development can be made to work together in culturally profound ways. He begins in what seems to be the most pragmatic of ways, describing how presidential politics and federal budgets directly express the moral attitude of the American government with regard to the nation's history. This profound reality then leads him to offer highly informed, culturally penetrating case studies the African American Community, and the Veterans Curation Programme, which includes his work in such widely different situations as the location of African American burials in Georgia and the identification of executed Iraqis in mass graves carried out by Saddam 
Hussein. The significance of these examples went well the "Beyond Archaeology" programme Joseph participated in providing in each case a variety of public outcomes that enhanced not only historical accuracy and heritage. In the Veterans Curation Project, archaeology is shown to have psychological benefits for veterans as well as career training tied to the lives they have led.

Laurence Bartram confronts the bottom line question for all anthropology students (from $\mathrm{BA}$ to $\mathrm{PhD}$ ); how can one make a living? He directly rebuffs the most prevalent answer to this question, "You cannot", by using his personal story of transitioning from academic archaeology to the arena of biomedical research. He parses out the general and specialized skills he learned as a faunal analyst. Counter to many people's beliefs that such a technical field would have a limited field of employable prospects, Bartram describes a "smorgasbord" of skills he gathered to prepare him for an unknowable, ever-changing employment market.

Ben Resnick's work with US Military veterans illustrates how public archaeology can engage communities to learn about their personal histories in ways that allow them to present military history to the public. His projects, as many of the others in this volume, demonstrate how learning the practice of archaeology prepares students and professionals by teaching them highly marketable skills even if archaeology turns out not to be the pathway they follow for career development in the long run.

\section{Archaeology is a Public Good}

In the 1960s, the legendary archaeologist Lewis Binford signalled a revolution in archaeological thinking and training, when he implemented Willey and Phillip's 1950s clarion call that "Archaeology is anthropology or it is nothing". This "New Archaeology" was introduced when we, the editors, were just beginning to hone our skills as novice students. We were ushered into a world in which the role of archaeologists as collectors of data was displaced by a model that mandated collection and integration of data within the context of the human culture. Previously, archaeology was about building timelines, establishing cultural sequences of the prehistoric and historic past, and setting boundaries of human activity and achievements. The mission of the New Archaeology was to model human behaviour from its material remains.

We would argue now that even those days are over. A "Newer Archaeology" must be directed to the public good. The profession can and must recalibrate to develop multiple platforms with an eye towards relevance in an age of crisis. Our volume's examples show that community sustainability can be perpetuated through eco-heritage tourism, educational venues 
for students from $\mathrm{K}$ through $\mathrm{PhD}$, and as a vital part of community identity and pride. More generally, archaeological practice reframes the cultural-historic context required for the transfer of cultural knowledge to successive generations along with the cultural skills for future success. And the anthropological edge is transformed to an applicable backdrop, as archaeologists explicitly understand that future generations require an understanding of the past to best adapt to the future. Today's younger generations will be pioneers coping with unpredictable social, natural, and physical environments (Mead 1970).

As such, archaeology brings much more to the public than a story of the past. It offers a set of soft and analytical skills that are positioned and re-positioned to many, if not most, areas of the twenty-first century's everchanging employment landscape. Thinking and practicing archaeology draws upon broadly relevant skills, including writing, presenting, storytelling, and systematically collecting information. It offers a broad perspective on the significance of technology for human communities and teaches cutting-edge computer, field surveillance, and internet research skills. We would argue that this Newer Archaeology draws upon three epistemological perspectives: the Humanities, the Social Sciences, and the Sciences. Humanists focus on the human condition, past and present, in all of its diversity. Humanists' methods, such as recording oral histories, tend to be qualitative and narrative. Social Scientists complement the humanist approach by bringing quantitative data collection and analysis such as systematic surveying, interviewing, and statistical analysis to interpret patterns of human cultures including their material aspects, and individual behaviours. Finally, Scientific archaeology adds the realm of the scientific expertise and technique through the widening reach of innovative new methods of radiometric dating, remote sensing, and sophisticated mapping methods. The systematic and repurposed disciplines of geology, climate, as well as the evolutionary anatomical study of plants and animals are now applied to past human (archaeological) records of how ancient societies coped with environmental challenges initially piloted by climate change. Archaeologists think and practice within one or more of these perspectives-Humanities, Social Science and Science-as they build knowledge of the past, the development of theory, the application of method and technique, and the critical thinking skills required for interpretation.

This set of papers brings together archaeologists deeply experienced in a broad array of archaeological venues, such as universities, CRM firms, heritage centres, tribal centres, museums, government agencies, and the corporate biomedical world to discuss the social benefits and corporate opportunities of studying and practicing archaeology with the public good in mind. These developments converge around the utility of our field to help in making our world a more sustainable place for future generations. 


\section{Acknowledgements}

This volume began as an SAA symposium in Albuquerque, New Mexico, the USA. We wish to acknowledge and thank the participants, most of whom are published here, for not reading their presentations and even more-so for using the symposium to help launch this special issue. The issue itself would not have been possible without the professional, expertise diligence and encouragement from my editor Juliet Helmke, who copy-reviewed each manuscript multiple times and provided the wherewithal to tie up the loose ends necessary to make our arguments into a coherent whole. Any mistakes and misstatements are fully owned by the guest editor.

\section{References}

Binford, L.

(1962). Archaeology as anthropology. American Antiquity, 28, 217-225.

(1978). The Huger survey and excavation: an exercise in site definition. Columbia: South Carolina Archaeo Logical Society.

Green, S.

(1977). The Huger survey and excavation: what is a site? Columbia: South Carolina Institute of Archaeology and Anthropology Colloquium series.

Green, S., \& Brooks, M.

(1978a). Determining the extent and variability of archaeological sites in temperate forest localities, M. Brooks, Symposium: Non-structural site discovery in heavily vegetated forests, F. McManamon. Tucson, Arizona: Society for American Archaeology.

(1978b). There is no such thing as an archaeological site. Tucson: Annual Meeting of Society for American Archaeology.

Green, S., \& Green, G. M.

(1999). The baseball diamond as American landscape Cooperstown Symposium, edited by P. Rutkoff, McFarland Press.

Heaney, S.

(1972). The sense of place. In Preoccupations: selected prose 1968-78. Farar, Strauss and Giroux: New York.

McGimsey, C. R.

(1972). Public archaeology. New York: Seminar Press.

Poplin, E., Norris, J., Wolfe, C. B.

(1978). Archaeological reconnaissance of the Mt. Holly Plantation. University of 
South Carolina Scholar Commons Research Manuscript Series. University of South Carolina, Columbia.

Poplin, E., Norris, J., Wolfe, C. B., Brockington, P.

(1979). Archaeological reconnaissance of six road relocations in Elberton county, Ga. University of South Carolina Scholar Commons Research Manuscript Series, University of South Carolina, Columbia.

Willey. G., \& Phillips, P.

(1958). Method and theory in archaeology. University of Chicago Press.

Publisher's Note Springer Nature remains neutral with regard to jurisdictional claims in published maps and institutional affiliations. 